\title{
Research of the Third Party Logistics Service Platform Design of Railway Oil Supply Chain
}

\author{
Zhiyuan Wang ${ }^{1, a}$, Shouwen $\mathrm{Ji}^{1, \mathrm{~b}}$, Yun Lan ${ }^{2, \mathrm{c}}$ and Xianbo Cui ${ }^{2, \mathrm{c}}$ \\ ${ }^{1}$ MOE Key Laboratory for Urban Transportation Complex Systems Theory and Technology, Beijing \\ Jiaotong University, Beijing 100044,China \\ ${ }^{2}$ CRM E-Commerce Tech. Co., Ltd, Beijing 100088,China \\ alzyz09193@163.com, bshwji@bjtu.edu.cn, 'lany@crmec.com.cn
}

Keywords: Service platform; railway oil supply chain; third party logistics; IT architecture.

\begin{abstract}
The management of railway oil supply chain has significant effort on ensuring railway transportation, reducing oil inventory and decline the costs of railway transportation. The paper introduces the target, business mode, service function and IT architecture of the third party logistics service platform of railway oil supply chain. The service function includes central application and the external field application, IT architecture is constructed by J2EE standard. The service platform uses service oriented application architecture based on SOA, providing a basement for the management of railway oil supply chain.
\end{abstract}

\section{Introduction}

The railway transportation plays an important role in the comprehensive transportation system of China, and the number of diesel locomotives covers a large part of the total number of locomotives. In 2015, China's railway owned locomotive 1 million units, up to 49\% of the proportion of the total number of the railway locomotive. The annual fuel consumption is more than 300 million tons, and the railway fuel inventory is about 15 million tons, occupying a total capital of 600 million yuan. It is important to efficiently and economically organize the railway diesel oil supply and to do a good job in diesel fuel management, which has a significant meaning on ensurance of railway transportation, reduction of oil inventory and funds and decline of the costs of railway transportation [1].

The oil demand of railway transportation has several characteristics including large amount of requirement, wide oil distribution points scale, varieties of multi label, transportation of large span, technical quality requirements, supply timeliness requirements high, all-weather security of supply, strong constraints on transportation cost etc. Thus it requires railway fuel supply for perfect system, professional management and scientific organization [2]. In the support of the national support program, China Railway Materials Commercial Corp and Beijing Jiaotong University research the third party logistics service platform of railway oil supply chain. This paper introduces the construction target, the business model, overall system function design, and the IT architecture of the platform.

\section{The Construction Target}

To construct a unified railway oil supply chain management system, realizing the data exchange among railway bureaus, railway bureau to the depot and material company to branch material companies vertically, achieving the data exchange between the railway system and the material system horizontally. Thus oil can be supplied accurate and be managed well. To organize a supply chain technology platform of demand driving, supplying orderly, low cost, well service and rapid response. Then to unify the supply business distributed in the railway, material system units at all levels into the railway oil supply chain management system through the process of demand management, planning management, shipping management, scheduling management, oil collection management, inventory management and payment management. To construct the basic unit of railway fuel oil management with the principle of safety, accuracy and stability. To achieve the 
accurate distribution and record of the oil on the oil injection system; to achieve real time monitoring of oil inventory in reservoir area on the inventory management system. Field application, as the system distribution in railway main oil operating point of the data collection points, to provide accurate and real raw data for the application of central.

\section{Business model analysis}

The application range of the third party logistics service platform of railway oil supply chain involves the CRM Co. Ltd, the nine branches, oil marketing companies, and 18 railway bureaus, 50 multiple depot, 300 multiple oil and the relevant departments of railways. The relationship graph is as shown in the Fig.1.

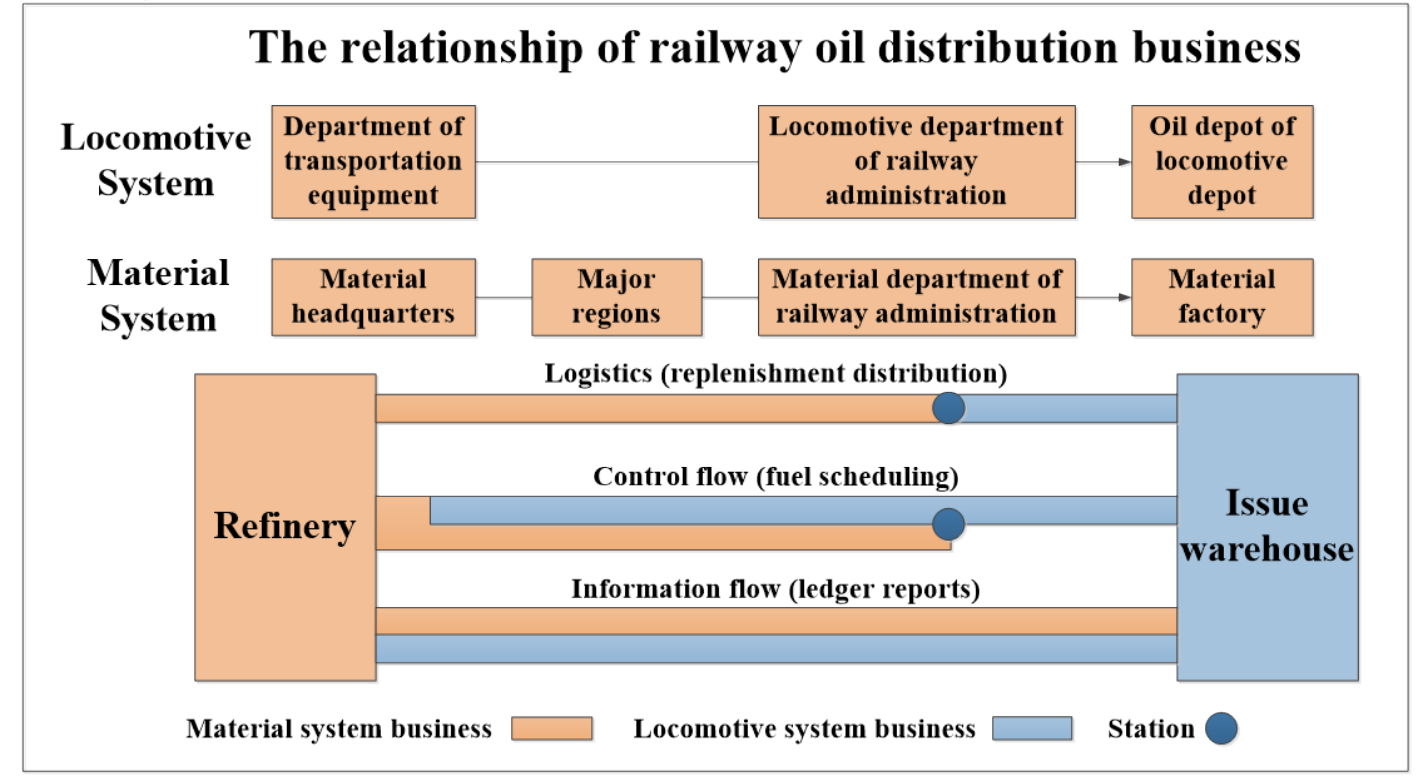

Fig. 1 Supply chain management business relationship diagram

\section{System Overall Functions Design}

The platform is a unified business processing system consist of central application (railway oil supply chain management system, railway oil supply chain analysis and decision system) and the application of the external field (railway oil depot intelligent management system, railway oil supply intelligent management system) [3].

The central application realizes efficient collaboration of the process of the railway oil demand planning management, purchasing management, supply management, storage management, payment management, settlement management and data statistics through the unified application software integrated supply and management information system [4].

The field application builds an automatic network data measurement and control system by refueling equipment and monitoring equipment deployed in the main railway locomotive depots, monitoring the receipt, development and storage status of oil in real time.

The third party logistics service platform of railway oil supply chain can form a collection of system data through the data exchange between the central application and field application, providing fine management ability [5]. The overall functions architecture of the platform is shown in Fig.2. 


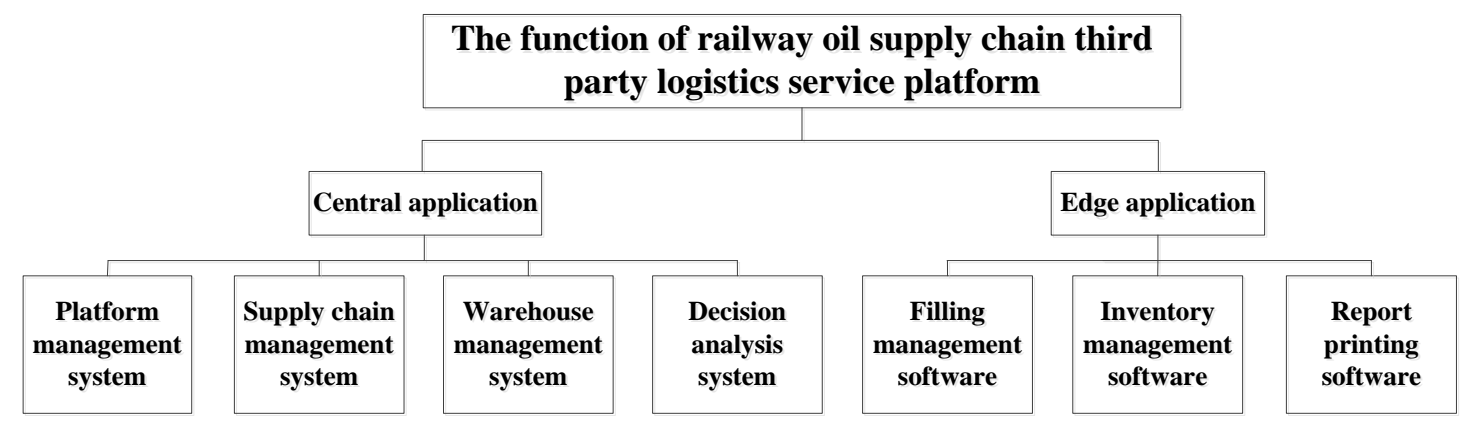

Fig. 2 Platform function structure diagram

(1)Oil Supply Chain Management System

The oil supply chain management system achieves the effective communication of various business aspects and business links of railway oil supply, breaking the information isolated state in the traditional operation mode, realizing the information sharing and information equivalence in the process of supply, transportation, storage and distribution. Under the support of the system data set, the entire oil supply and use system is organically aggregated within the system. Between the upstream and downstream links, the management and operating institutions, the supply and marketing of information, it forms the situation of information equivalence. For one thing, it creates favorable conditions for accelerating logistics and reducing inventory costs under the premise of ensuring the safety of railway oil supply. For another, it provides support for accurately grasping the state of operation and scientific decision-making. The specific function is shown in Fig.3.

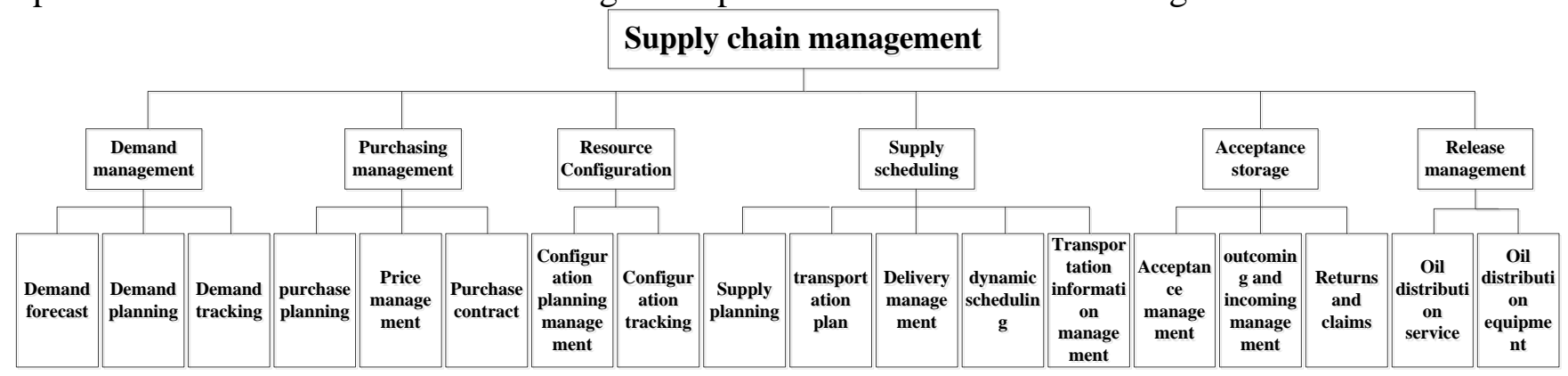

Fig. 3 Supply management structure diagram

(2)Analysis and Decision System

The analysis and decision making system fully analysis the relationship of business data and regulate and aggregate a large amount of data information. Through data warehouse and decision support technology based on comprehensive analysis, checks with intuitive, hierarchical organization, progressive refinement, user personalized customized data statistics. Analysis and decision mainly includes service business data analysis and business data statistics for railway maintenance management at all levels.

(3)Oil distribution intelligent management system

The oil distribution intelligent management system consists of automatic filling machine, industrial control equipment, application software and auxiliary equipment such as power supply, printer, pipeline, etc. which are for the locomotive depot oil daily locomotive oil and oil production led the issuance of work. The system can realize the accurate distribution under artificial control conditions. It supports two types of distribution for locomotive collar and oil production, sending planned amount of instructions to the automatic filling machine to make the exact payment. It also supports for additional planning and the payment of small ticket printing and document collection. It can accurately save the oil distribution of the historical data, thus the job data can be uploaded to the central application and it can receive the central application issued instructions; In addition, it has system state detection alarm, fault tolerance and fault oriented security mechanism.

Charging management system is the central control unit of railway oil distribution of intelligent management system, managing a wide variety of automatic peripheral equipment, completing the operation data of the terminal stage storage. It is responsible for operation data and system running 
data uploaded to the central system, which is also the system and user interface, accepting user's commands and completing the corresponding operation [6].

\section{Platform of IT Integration Framework}

The J2EE standard is chosen to be the standard of the standard of application system. The integration IT structure of J2EE are shown as Fig.4.

\section{Framework Information soft bus}

The third party logistics service platform of railway oil supply chain uses service oriented application architecture based on SOA. In the SOA architecture, ESB (Enterprise Service Bus) is an important part of the system. ESB provides connectivity infrastructure of SOA, which is the concrete embodiment of the Application Hub SOA architecture. The service that is published on the SOA architecture is the "user" of ESB, which is open to the service through the ESB to interact with the service system based on the SOA architecture. Their interaction requests are published and subscribed in the event of an event.

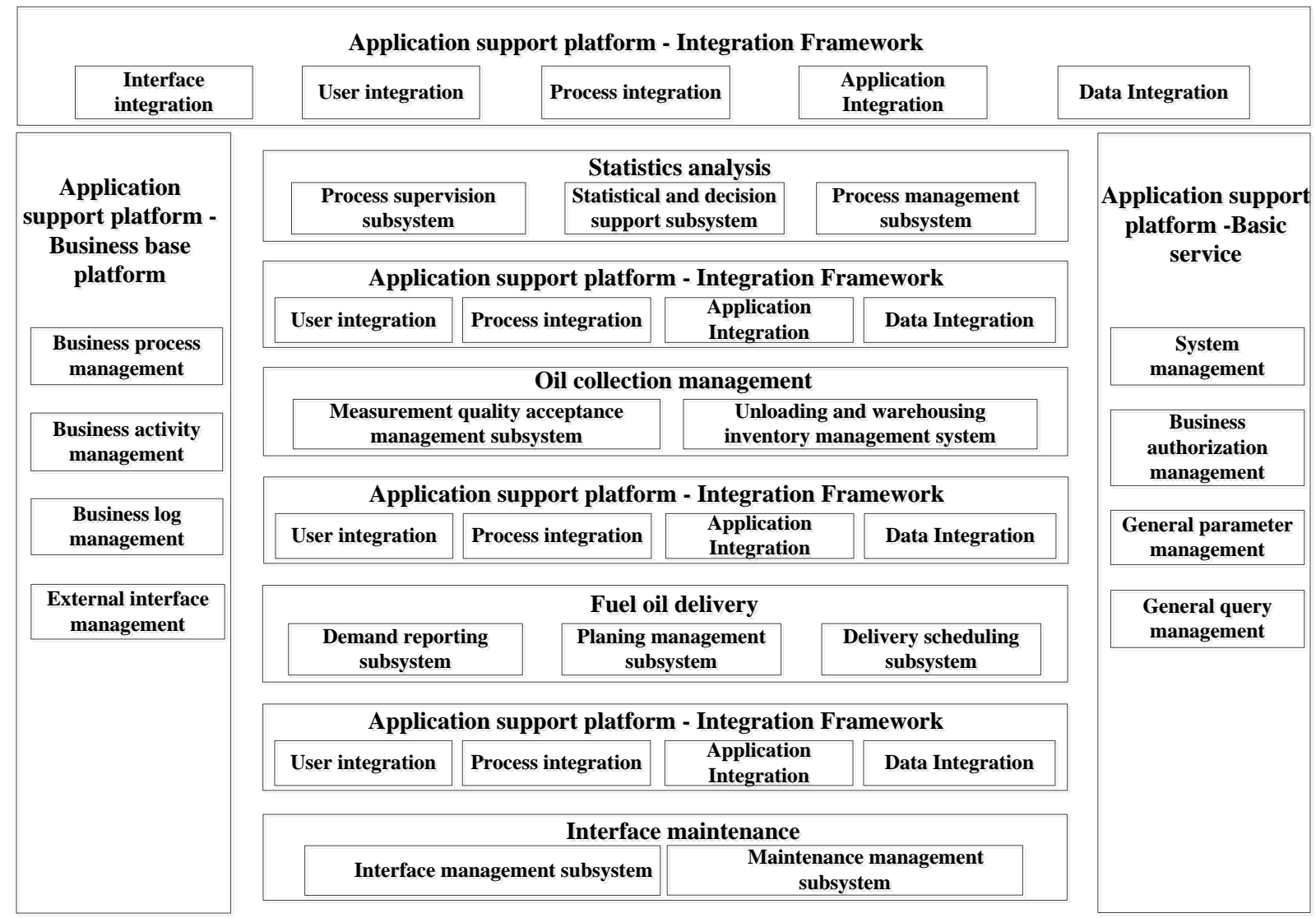

Fig. 4 System integration framework

The bus information technology, builds a hub for data and information exchange, exchange visits all the system data, and provide standard interface to facilitate and other system integration or exchange of information, as shown in Fig.5.

Information bus mainly provides services such as transport services, data routing services, data format conversion services, data processing services, and so on. Those services are realizes in the ESB. 


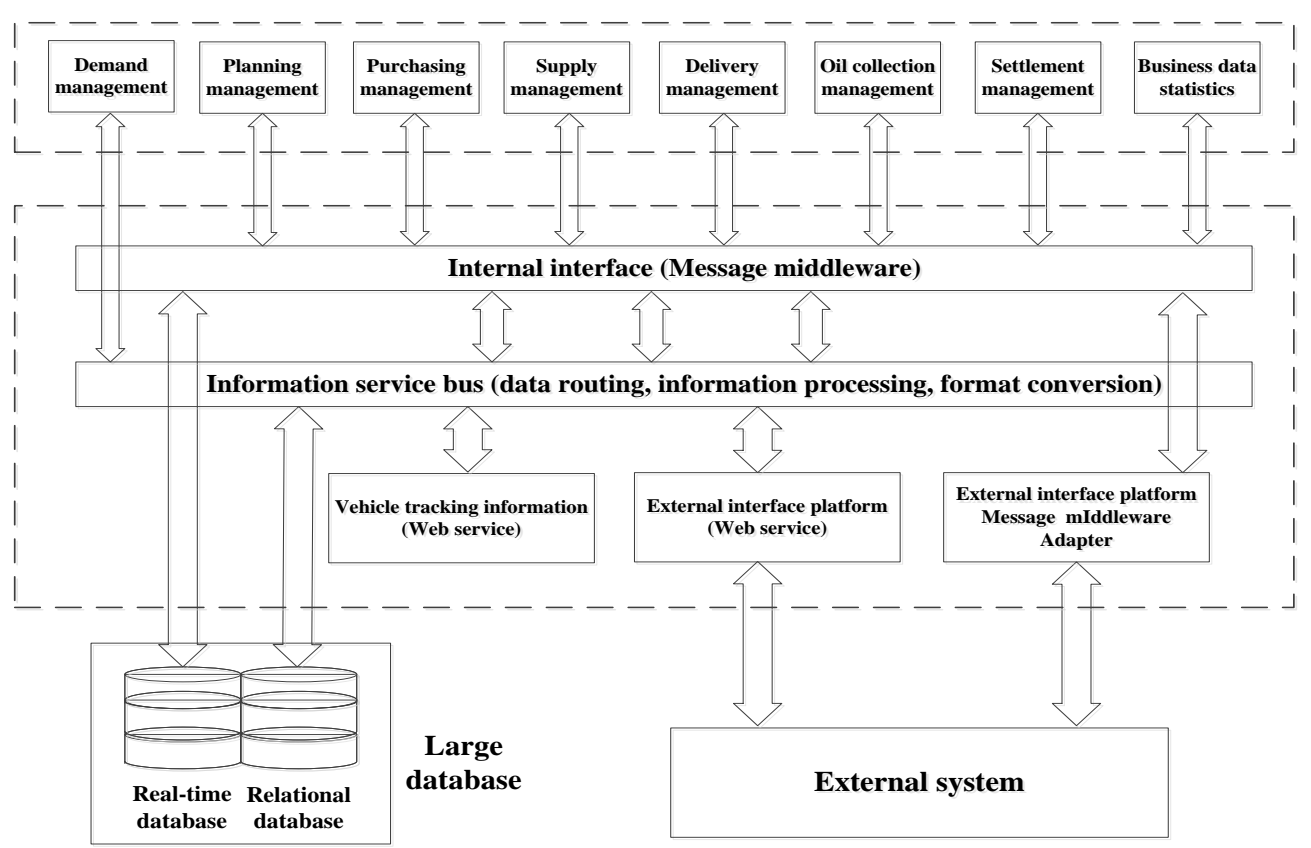

Fig. 5 Information bus structure

\section{Summary}

This paper introduces the construction background and the construction object of the third party logistics service platform of railway oil supply chain. Then it analysis the application subject and the business model of the platform. It also introduces the main function of the platform, including management system of oil supply chain, management system of oil distribution, system of decision analyzing and making. Finally it gives a brief introduction of the integration of the IT architecture based on J2EE, providing a basement for the management of railway oil supply chain.

\section{Acknowledgment}

The paper is sponsored by National Science-technology Support Plan Projects "Research and Application of the Third Party Logistics Service Platform of Railway Oil Supply Chain” (No. 2014BAH23F02) and "Research of Real-time Monitoring, Tracing and Management Technology of Supply Chain Logistics” (No. 2014BAH23F01).

\section{References}

[1]. G. Huijuan MA. Research on the Integration Supply Mode of Railway Fuel Based on Third-party Logistics [D].Beijing Jiaotong University.2013. In Chinese.

[2]. TingTing Huang.Research on Collaboration Degree and Performance Evaluation of Railway Oil Supply Chain [D].Beijing Jiaotong University.2012. In Chinese.

[3]. Xiao Wang. The Analysis on Value Chain of China Railway Oil Distribution and the Planning of Information System [D]. Beijing. Tsinghua University, 2004. In Chinese.

[4]. Archibald T W, Black D P, Glazebrook K D. Index ability and index heuristics for a simple class of inventory routing problems[J]. Operations research, 2009, 57(2): 314-326. In Chinese

[5]. Rajesh K.Singh. Developing the framework for coordination in supply chain of SMEs [J]. Business Process Management Journal, 2011, 17(4):619-638. In Chinese.

[6]. A.Ramesh, D.K.Banwet, R.Shankar. Modeling the barriers of supply chain collaboration [J]. Journal of Modeling in Management, 2010, 5(2):176-193. In Chinese. 